\title{
Exploration and Practice on Innovation and Entrepreneurship Education for Agricultural and Forestry University Students
}

\author{
J. Hu \\ College of Economics and Management, Sichuan Agricultural University, Chengdu, China \\ Q. Huang* \\ College of Forestry, Sichuan Agricultural University, Ya'an, Sichuan, China
}

\begin{abstract}
The education of innovation and entrepreneurship for university students is the need of era development, is a powerful driving force for national economic development and transforming, is an important content of the teaching reform of higher education. This paper deeply analyzes the basic connotation, the primary content, the main goal of innovation and entrepreneurship. And the main problems of that are also analyzed, and then some conclusions and measurements of the education of innovation and entrepreneurship are put forward for the educational and teaching reform.
\end{abstract}

KEYWORD: Innovation and entrepreneurship education; Agricultural and forestry universities; Exploration and practice

Economic development and social progress increasingly rely on science and technology innovation and the cultivation of innovation and entrepreneurship talents in the twenty-first Century, which is dominated by knowledge economy. Colleges and universities not only play an important role but also shoulder sacred mission in training innovation and entrepreneurship talents.

As early as 1998 UNESCO thought that training the students entrepreneurial skills and entrepreneurship spirit should be taken as the primary goal of higher education, to enable graduates to become not only the job seekers but also the creators of jobs. Chinese government has also paid much attention on innovation and entrepreneurship education because it is the need of the development of the times, is also the powerful force of economic development and transformation. Moreover, it is the main contents of the higher education.

\section{THE BASIC CONNOTATION OF INNOVATION AND ENTREPRENEURSHIP EDUCATION}

There are two viewpoints on the basic connotation of innovation education. One thinks it is an education activity for the purpose of cultivating innovative consciousness, spirit, thinking, ability, personality and talents. The other deems that it is education activities which can make the students carry out innovation. That means any education which is for the purpose of training innovation quality and enforcing innovation ability can be called innovation education. There are also two viewpoints of entrepreneurship education. One thinks that entrepreneurship education is an education activity for cultivating students' entrepreneurial consciousness, quality and skills to make them adapt to the social life, improve their ability in the courses of entrepreneurship activity. The other reckons that there are three goals for entrepreneurship education. The first one is to know entrepreneurship by learning; the second one is to be a man with entrepreneurial quality, spirit and ability. The third one is to become an entrepreneur by learning. It can be seen that innovation education and entrepreneurship education share the common goal of training the students' innovative spirit and practical ability. Innovation and enterprise education should be uniform from the students' perspective, which are behavior agent. In all, the basic connotation of innovation education and enterprise education is innovation and creativity. It is a quality education activity in order to train the innovation and enterprise consciousness, Personality, knowledge, thought and ability for developing and improving the trainee's comprehensive quality with the harmony of teaching and practice.

Different from traditional education, innovation education and entrepreneurship education pay much attention on training students' ability and entitle more option to students. This embodies the founder mental requirement of social-economic development 
and will be an important idea of reforming Chinese higher education.

\section{THE BASIC CONTENT AND GOAL OF INNOVATION AND ENTREPRENEURSHIP EDUCATION}

\subsection{The basic content of innovation and entrepreneurship education}

\subsubsection{Idea education of innovation and entrepreneurship}

Innovation and entrepreneurship idea is referred to understanding of the significance, goal and behavior. Idea education of innovation and entrepreneurship can promote idea of that renew, avoid blind employment, guide their thoughts actively.

\subsubsection{Inculcating innovation and entrepreneurial consciousness}

Innovation and entrepreneurial consciousness is reflection of innovation and entrepreneurial activity is a personal psychological tendency to promote entrepreneur behavior, including the need, motivation, will. Need and motivation are the source of innovation and entrepreneurship while will is the force of that. Both of them dominate innovators' and entrepreneurs' attitude and behavior. Education of innovation and entrepreneurial consciousness can help college students enlarge their business understanding and guide them to set goals.

\subsubsection{Innovation and entrepreneurial learning}

Knowledge is the fulcrum of innovation and entrepreneurship, innovation and entrepreneurial knowledge not only includes the policy, legal, also contains the necessary professional knowledge and enterprise management. Without the knowledge or with a single knowledge structure, it is difficult to succeed in entrepreneur. Innovation and entrepreneurship education for college students should set courses according to the talent training goal of diversification, Inter-disciplinary to make them adapt the future position or entrepreneurship

\subsubsection{Innovation and entrepreneurship spirit incentive}

The spirit of innovation and entrepreneurship is the good character which entrepreneur manifest in their innovation activities such as courage to forge ahead, pioneering and innovative, working hard and persevering, dare to bear, the unity cooperation. A certain experiment shows the most successor have the above personal characters. So encouraging the students to pioneer, and innovative, be bold and guiding them to develop themselves is one of important ways to train their innovation and entrepreneurship potential.

\subsubsection{The cultivation of innovative entrepreneurial qualities}

Enterprise must possess certain qualities, including political quality, moral quality, professional quality, cultural quality, psychological quality and physical quality etc. Among them, political quality is related to the right way to endeavor; professional and cultural quality play an important technical role and moral quality play a non-technical one. Psychological quality is directly related to the entrepreneurial response to frustration and adversity and body quality is the premise and foundation of that. Innovation and entrepreneurship education should take the education of ideal and faith as the breakthrough point, strengthening the students' ideological and moral education, enforcing their social consciousness, training their good characters in order to contribute Chinese improvement.

\subsubsection{Enhancing the innovation ability}

The ability of innovation and entrepreneurship contains cognitive ability of that, such as cognitive environment and grasping opportunity, professional or occupation ability including management, application of science and technology, social and adaptive ability. Although all of them are related to innate character and temperament, they are mainly obtained from education and practice. So innovation and entrepreneurship education should combine theory with practice, building diversity practice teaching platform and providing practice opportunity as much as possible for students.

\subsection{The main objectives of innovation and entrepreneurship}

\subsubsection{Cultivating optimistic and aggressive trainee}

Innovation and entrepreneurship education focuses on training students' sense of social responsibility and positive attitude and oppose to traditional education. By innovation and entrepreneurship education, the students must depend on their own initiative, instead of studying passively. By this way, it can make students adapt to the sociality and become useful man.

\subsubsection{Cultivating students with strong enterprise and innovation ability}

Enterprising and innovation ability is the potential for an entrepreneur. But the goal of that cannot make all trainees become entrepreneurs, the point of enterprising and innovation education is training their innovation and entrepreneurship consciousness, spirit and ability. 


\subsubsection{Cultivating students to make them study diligently, be good at learning and lifelong learning}

It plays a vital role that forming a good habit of studying diligently and being good at learning and lifelong learning. Obtaining, digesting, absorbing, innovating all kinds of knowledge and technology is very important for development and improve of personal, collective, country and even the human being.

\section{MAIN PROBLEMS OF EDUCATION ON INNOVATION AND ENTREPRENEURSHIP EDUCATION IN CHINA}

\subsection{Backwardness of teaching ideas}

On agricultural bias for a long time, most students in agricultural and forestry universities have a weakness in self-awareness, which makes be short of study force and weak sense of enterprising. So, it is very important to train students' spirit of innovation and entrepreneurship and renew the educational ideas.

\subsection{Lack of professional teachers}

The lack of professional teachers is a common problem in the innovation and entrepreneurship Education. It needs the teacher not only have speculative knowledge also have practice knowledge. However, most teachers which assume the course of innovation and entrepreneurship education have no above knowledge. Owning to be short of the characteristics and rules of that, or have few knowledge of agricultural procedure and character, the teaching only play much attention on the theory while ignore the practice. All of the above is difficult to meet the need of innovation and entrepreneurship education.

\subsection{The curriculum system is not perfect}

At present, the course contexts of innovation and entrepreneurship education in many agricultural and forestry universities with being lack of the professional textbooks and have no connection with the professional education of the subjects. It makes a large gap between the learning knowledge and the modern agriculture.

\subsection{Lack of practice}

Innovation and entrepreneurship is originally practice activity, so practice is the key way to train and improve the ability of innovation and entrepreneurship education. Influencing on traditional idea and educational institute, it is short of practice teaching. Because of this, many students are bad at social adaption and competitiveness.

\subsection{Unsound in supporting system}

Organization guarantees system, practice teaching platform, digital network system, teachers, evaluation system, financial and campus cultural are the basic hardware and software conditions or supporting system. Without them, training innovation talents is impossible. But all the factors are short during the innovation and entrepreneurship education.

\section{MEASUREMENTS OF ESTABLISHING INNOVATION AND ENTREPRENEURSHIP EDUCATION SUPPORTING SYSTEMS}

\subsection{Organization}

The organization should be led by the Party committee and administration, be cooperated by all administration and be interacted by all faculties. Among them, the Party committee bears the responsibility of leading; the president is responsible for implementing. Students' Affairs Division is responsible for ideological education and behavior management. Office of academic affairs and the department of science and technology are mainly responsible for the organization, coordination of teaching and research. The personnel department is responsible for coordination, incentive, evaluation and supervision of the staff. Logistics management department ought to service directly for teachers' and students' daily life. The faculties take separate responsibility and assume specific implement.

\subsection{Institute}

To inspire the teachers and the students participate actively, the institutes should be established such as teaching quality management, credit system, Teaching evaluation and Teaching supervision.

\subsection{Funds}

The authorities of the university should put money to improve the teaching condition and carrying out innovative experiment, scientific research, professional skills competition, business plan design competition and entrepreneurship project should be funded.

\subsection{Campus culture}

The spirit of innovation and entrepreneurship needs to breed in a certain cultural atmosphere so the campus culture should be enforced to guide to form 
the good environment for encouraging the individual innovation and entrepreneurship.

\section{REFERENCES}

[1] Xu Detao. Research on college students' innovation and entrepreneurship education. Master Degree Paper of Shandong University, Shandong University, 2013.
[2] Guo Jinhui, He Linchun. Preliminary study on entrepreneurship education in agricultural colleges. Education Exploration, 2013, (1): 152-154.

[3] Bao Kunjin, Jiang Yuansheng. The practice and exploration of creative undergraduate talents cultivation system in universities. Higher Education Forum, 2012, (10):44-48, 61

[4] Deng Liangji, Zeng Weizhong. Exploration on Entrepreneurship Talent Training and Practice in Sichuan Agricultural University. Higher Agricultural Education, 2012, 2 (2): 3-5. 